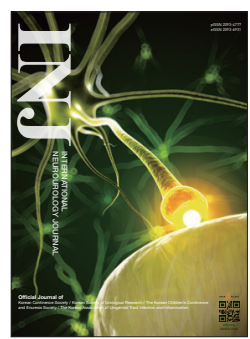

\title{
Past, Present, and Future in the Study of Neural Control of the Lower Urinary Tract
}

\author{
Jin Wook Kim ${ }^{1}$, Su Jin Kim² , Jong Mok Park ${ }^{3}$, Yong Gil Na ${ }^{3}$, Khae Hawn Kim ${ }^{3}$ \\ ${ }^{1}$ Department of Urology, Chung-Ang University, Seoul, Korea \\ ${ }^{2}$ Department of Urology, Yonsei University Wonju College of Medicine, Wonju, Korea \\ ${ }^{3}$ Department of Urology, Chungnam National University Sejong Hospital, Chungnam National University, Sejong, Korea
}

\begin{abstract}
The neurological coordination of the lower urinary tract can be analyzed from the perspective of motor neurons or sensory neurons. First, sensory nerves with receptors in the bladder and urethra transmits stimuli to the cerebral cortex through the periaqueductal gray (PAG) of the midbrain. Upon the recognition of stimuli, the cerebrum carries out decision-making in response. Motor neurons are divided into upper motor neurons (UMNs) and lower motor neurons (LMNs) and UMNs coordinate storage and urination in the brainstem for synergic voiding. In contrast, LMNs, which originate in the spinal cord, cause muscles to contract. These neurons are present in the sacrum, and in particular, a specific neuron group called Onuf's nucleus is responsible for the contraction of the external urethral sphincter and maintains continence in states of rising vesical pressure through voluntary contraction of the sphincter. Parasympathetic neurons originating from S2-S4 are responsible for the contraction of bladder muscles, while sympathetic neurons are responsible for contraction of the urethral smooth muscle, including the bladder neck, during the guarding reflex. UMNs are controlled in the pons where various motor stimuli to the LMNs are directed along with control to various other pelvic organs, and in the PAG, where complex signals from the brain are received and integrated. Future understanding of the complex mechanisms of micturition requires integrative knowledge from various fields encompassing these distinct disciplines.
\end{abstract}

Keywords: Periaqueductal gray; Pons; Urination; Nervous system

- Research Ethics: JWK, SJK, and KHK, members of the Editorial Board of International Neurourology Journal, are the authors of this article. However, they played no role whatsoever in the editorial evaluation of this article or the decision to publish it.

- Conflict of Interest: No potential conflict of interest relevant to this article was reported.

\section{INTRODUCTION}

The standardization of urodynamic evaluations serves both as a boon and a curse to current day clinical neurourology. In many cases, the evaluation of a clinical case of dysfunction in urination progresses no further than identifying the abnormal spinal reflexes gleaned from bladder and abdominal pressure sensors, and the accompanying perineal myogenic response. Seldom does a clinical study for novel pharmaceuticals progress beyond the bladder mucosal receptor, and the entirety of discussion surrounding basic clinical pharmacology in urology often ends with whether the substance crosses the blood brain barrier.

Despite these drawbacks, neurourology has progressed slowly and steadily since the days when the voiding nuclei were first identified and nominated, if not clinically, then at least at the bench. Recent developments have taken advantage of optoge-

Corresponding author: Khae Hawn Kim id https://orcid.org/0000-0002-7045-8004 Department of Urology, Chungnam National University Sejong Hospital, Chungnam National University, Chungnam National University Sejong Hospital, 20 Bodeum 7-ro, Sejong 30099, Korea E-mail: kimcho99@cnuh.co.kr

Submitted: August 30, 2020 / Accepted after revision: September 8, 2020 
netics, the marriage of genetic manipulation to neurology which allowed selective control over distinct nuclei, to build upon the developments begun more than a hundred years ago in the early ages of neuroanatomy.

This review aims to reiterate classical concepts of voiding in the language of today's new developments in the science of neurourology.

\section{LOWER MOTOR NEURONS}

\section{Autonomic Neurons and the Internal Sphincter}

The principal components of voiding and storage comprise of voluntary and autonomous components. The autonomous components are commonly described by their gross anatomical designations which convey the organ-based modular understanding which has already been understood in depth for nearly 200 year [1]. The understanding, and also the naming, of the muscular portion of the bladder wall, its layers and the general concept of its function has been generally in agreement since the times of Galen, to Vesalius and to the present day.

The internal sphincter, however, has faced much contention through its history, as more classical texts have described a clear sphincter-like arrangement [2]. Of note, however, Griffiths observes that, while there is no definite sphincter-like arrangement in the bladder neck, compared to other animals, the functional internal sphincter does not terminate at the bladder, but is of a contiguous system which extends down to the urethra, with humans extending to about half an inch, whereas in cats the length may reach up to 2 inches. Unfortunately, these teachings are not well appreciated, and even modern textbooks often depict the internal sphincter as a notable bulging muscle group at the neck of the bladder [3]. As such, modern anatomists are constantly required to 'rediscover' the functional internal sphincter in humans and animals $[4,5]$.

In this context, the distinction to diverge from organ-based anatomy and embrace a more functional understanding seems prudent. Therefore, in this paper, which focuses more on the neurological control of these organs, it is suffice to consider the division among only the voiding and storage mechanisms controlled by autonomic functions on one part, and the voluntary control exerted on the external urethral sphincter (EUS).

The autonomic control of voiding and storage is maintained by the sympathetic and parasympathetic nerves. The sympathetic function of voiding is maintained by neurons originating in the lateral horn of thoracolumbar cord segments T11 through L2 of the overall thoracolumbar outflow, which encompasses T1 to L2 [6]. The parasympathetic outflow neurons are located in the sacral (S2-4) segments of the overall craniosacral parasympathetic outflow (which includes the cranial nerves $3,7,9$, and 10). By principle, the sympathetic ganglia connect the preganglionic and post ganglionic neurons at the paraspinal ganglia, whereas the parasympathetic ganglia are terminal or intramural ganglia located in proximity to the bladder, in this case the inferior hypogastric plexus (IHP) [7,8].

It is often taken as a binary division that the sympathetic outflow passes through the hypogastric nerves, whereas the parasympathetic outflow is associated with the pelvic splanchnic nerves. In actuality, post ganglionic divergences of neurons range from 4 to 20 , resulting in several small microscopic fibers that could not definitely be determined its origin without advanced methods [9]. Recently, Alsaid et al. [10] showed coexistence of both parasympathetic and sympathetic fibers for both courses. Li et al. [11] showed the scant paucity and the delicate nature of these neurons scattered within the IHP, consisting about $4 \%$ of the cross section. Modern investigations of the IHP underscores the significant lack of tools available to classical anatomists to understand functional neurourology.

As such, the general understanding is that the end organ detrusor muscles, contiguous from the bladder to the urethra, are autonomically innervated in function by parasympathetic and sympathetic outflows.

\section{Onufrowicz's Nucleus and the EUS}

In contrast to the autonomic voiding/storage apparatus and its innervation, the somatic control of voiding and the EUS remain distinct. There has been no major misunderstanding concerning the presence of an EUS. While the muscular structure has always been apparent, the discovery of distinct nerve cells by the Polish American Bronislaw Onufrowicz (Onuf for short) had been fortuitous [12]. Onuf had noted the distinct morphology of the nuclei and had further associated its function to the bulbocavernosus and ischiocavernosus muscles, concluding its primary function in penile erection. It was only until latter studies that the range of its functional control expanded to the anal and externa urethral sphincters [13-16]. The neurons from Onuf's nucleus maintains continence of micturition and defecation through the perineal nerves [17].

Modern understanding of the EUS via Onuf's nucleus involves a complex interplay between the autonomic and somatic nerves. Even though these neurons participate in the process of 
signal transmission through similar basic mechanisms as other neurons - via neurotransmitters that are secreted by the presynaptic neuron and bind with postsynaptic receptors - their axons contain fewer dense core vesicles and secretory granules than are found in autonomic nerves [18]. The motor neurons of these nuclei are rich in serotonin (5-HT) and norepinephrine (NE) receptors and are activated by L-glutamate, a neurotransmitter that is the anionic form of glutamic acid. If activated by 5-HT and NE, the guarding reflex, which suppresses urination, occurs and prevents urination when abdominal pressure suddenly increases.

Regarding incontinence, a 3-layer muscle is involved in urine flow and continence that consists of an inner band of longitudinal smooth muscle, a middle band of circular smooth muscle, and a striated muscle known as the rhabdosphincter. This muscle is dominated by sympathetic neurons, parasympathetic neurons, and the somatic branch of the peripheral nervous system. First, sympathetic neurons are distributed in the longitudinal and circular smooth muscle layers, running along the hypogastric nerve and synapsing with sympathetic preganglionic neurons located in the upper lumbar spinal cord [17]. Parasympathetic neurons arise from parasympathetic preganglionic neurons located in the sacral spinal cord and are also distributed in the longitudinal and circular smooth muscle layers. Somatic nerves originate from motor neurons located in the ventral or anterior horn of the sacral spinal cord, i.e., Onuf's nucleus. The pudendal nerve also extends from Onuf's nucleus and directly controls the rhabdosphincter. The sympathetic storage reflex, which is also called the pelvic-to-hypogastric reflex, starts when NE is secreted in response to bladder stretching [19]. The somatic storage reflex, which known as the pelvic-topudendal or guarding reflex, occurs in situations such as laughter, sneezing, and coughing that induce a rise in vesical pressure due to increased abdominal pressure or detrusor pressure. LGlutamate, which is the primary excitatory transmitter in the reflex arc, triggers action potentials by stimulating $\mathrm{N}$-methylD-aspartate, a-amino-3-hydroxy-5-methyl-4-isoxazolepropionic acid, and transmembrane ionotropic receptors, and these action potentials stimulate the secretion of acetylcholine, thereby causing contraction of rhabdosphincter fibers [20]. It is thought that stress urinary incontinence occurs if this guarding reflex does not function properly.

The coordination between the somatic control of the EUS and the autonomic control of the detrusor muscles is an interesting phenomenon. While the actual act of voiding is an en- tirely autonomic execution of a set of responses, the initiation itself is entirely by somatic voluntary command. Similar associations exist in several other voluntary to autonomic responses, including swallowing, where the inferior constrictor (IC) muscle and the cricopharyngeal (CP) muscles interplay in a transfer of hands similar to voiding reflexes [21,22]. Different subtypes of amyotropic lateral sclerosis (ALS) can be seen to mirror these changes, as bulbar ALS involves speech and dysphagia, whereas spinal ALS is also known to involve Onuf's nucleus, thereby eliciting voiding disorders [23]. The connection from somatic to autonomic is most apparent during urodynamic studies, where the silencing of pelvic electromyographic activity before voiding is interrupted with intermittent bursts of EUS activity. Similar activity can also be seen between IC and CP during swallowing [24]. Where the similarity ends is also interesting, as the act of swallowing begins actively in amnio, while voiding is acquired in the early years of infancy. Hence, several studies have demonstrated a period of learning during which the electromyography signal gradually become suppressed during the reflexive voiding phase, only to reappear following spinal injury, as noted in cases of detrusor sphincter dyssynergia $[6,25,26]$. The plasticity of interneurons develops towards control from the upper motor neurons (UMNs), primarily from Barrington's nucleus.

\section{UPPER MOTOR NEURONS}

\section{Barrington's Nucleus, the M-Region, and the Pelvic Organ Stimulating Center}

Barrington's nucleus is located medial to the locus coeruleus in the pons. Its principal function was identified during discovery by F. J. F. Barrington, a urologist at University College Hospital, London, through a series of experiments published during the 1920s; borrowing the then novel stereotaxic surgical equipment from its pioneering developers, physiologist Robert Clarke and neurosurgeon Victor Horseley, Barrington performed needle destruction studies on cats whilst documenting its corresponding functional voiding changes [27].

Although, Barrington had discovered his eponymous nucleus with the intent to uncover the voiding center, neuroscience has since identified a variety of different populations within Barrington's nucleus, with some interesting topographic distinctions as well. The principal neurons in regards to micturition have been identified to be corticotropin-releasing factor-positive, which project to the spinal parasympathetic nucleus inner- 
vating the bladder [28]. Holstege et al. [29] distinguished Barrington's nucleus as the $\mathrm{M}$-region, in contrast to a more lateral field (the L-region) which controlled Onuf's nucleus, which would then, in turn, activate the EUS and other pelvic floor muscles, not only limiting to micturition and storage, but also to defecation and sexual activity.

The most recent terminology presents Barrington's nucleus as the pelvic organ stimulating center (POSC), as neurons in this group not only project to parasympathetic neurons eliciting micturition, but also to parasympathetic neurons to the uterus, the distal colon and rectum. In contrast, the L-region, caudal and ventrolateral $(\mathrm{VL})$ to the POSC is termed the pelvic floor stimulating center (PFSC), its stimulation activating the pelvic floor in general, via Onuf's nucleus, including the EUS and, returning to Onuf's original discovery, the bulbocavernosus and ischiocavernosus muscles [29-33]. Since Holstege [31] seems to have abandoned the terms M- and L-region for POSC and PFSC, respectively, the most modern nomenclature would be for the latter (Fig. 1).

\section{The Periaqueductal Gray}

The earliest studies on the periaqueductal gray (PAG) followed the seminal works of Barrington, by introducing lesions in cats [34]. Earlier studies focused both on micturition and the appar- ent psychological aspects that destruction of associated structures induced. The overall function of the PAG in total is too broad to cover in this review. However, the study of the PAG has been partitioned to 4 general anatomical locales that seem to have distinct functional properties: dorsomedial, dorsolateral (DL), lateral, and VL, which have distinct connections with the forebrain, brainstem, and nociceptive neurons of lamina I of the spinal cord and trigeminal nucleus. Concerning micturition, the DL and VL columns have been highlighted.

Whereas the pons has presented relatively centralized pathways for both voiding and active retention in POSC and PFSC, respectively, research into the PAG micturition control has shown an increasing tendency towards interconnection with complex functions. While the DL column projects modulatory gamma-aminobutyric acid signals, and the VL column projects primary glutamate signals to the POSC, each column also integrates various cranial pathways such as emotional, vocalization and motor functions [33,35-38]. The PAG shows a wide range of integration with various subsystems, including freezing vs. feeding in association with the cerebellum, sex and pain response, and vocal control [39-42].

PAG is distinct from the POSC in that sensory information on bladder filling passes through A $\delta$ fibers from detrusor muscles coursing through the dorsal horn and up the spinal cord

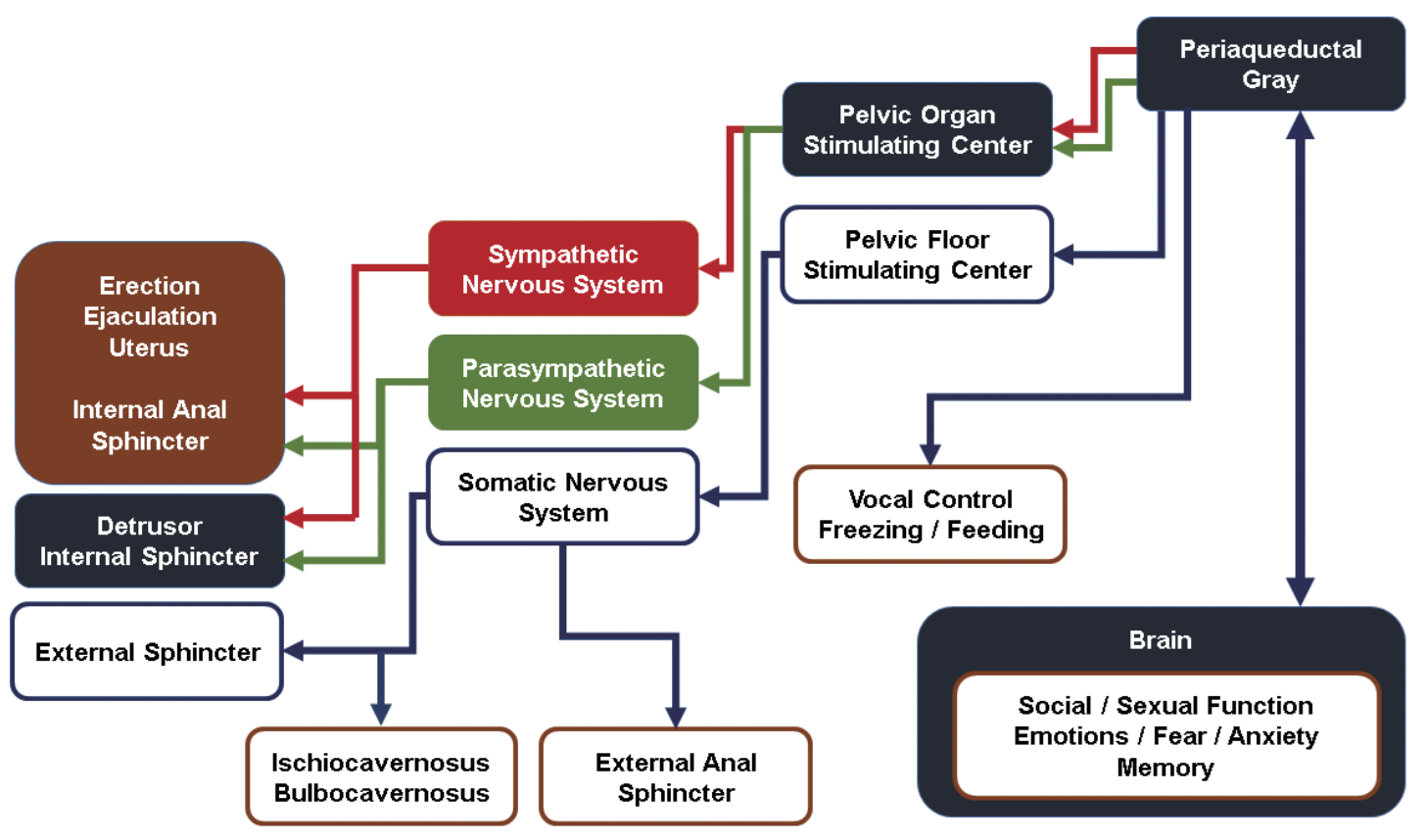

Fig. 1. Pathways depicting the general outline of pelvic organ stimulating center and pelvic floor stimulating center. These are gross outlines omitting interconnections afferent pathways, and specific control centers for functions other than micturition. 
are integrated here. In rats, this connection allows direct command to the POSC to initiate micturition [43]. However, in humans, and cats and dogs and other primates, the PAG does not decide micturition based on bladder filling information alone, and are subject to many brain structures [31,44]. Interesting, though, rats have also shown some degree of social modulation of stress retention $[45,46]$. As such, the difference between how the PAG integrates both peripheral signals with higher complex functions to direct voiding in the POSC and PFSC in humans and rats would be an interesting subject in understanding how our social and emotional controls of voiding develop. As such, Holstege [47] has termed this function of the PAG as the Emotional Motor System.

\section{Central Pathways}

The complex, but incomplete, understanding of the brain in control of micturition implicates various structures involved in the decision on when and where to void $[48,49]$. There is an understandable lack of concrete evidence, as presented so far in studies up to the mid brain. Most recent studies focus on functional magnetic resonance images (fMRI) limited to only a handful of subjects [50,51]. While the sensation of bladder distention and urgency has been associated strongly with the thalamus in rats, human studies show involvement of a plethora of other structures [52-55].

The hypothalamic preoptic area projects to the POSC, conferring a "safe signal" that it is permissible to void $[36,56,57]$. During voluntary urine withholding, blood flow to the cingulate gyrus significantly decreases, while the prefrontal cortex is active when micturition is taking place during involuntary withholding [58-61].

However, whereas the specific control of voiding and retaining urine generally ends with the motor control of the PAG, and then to the POSC and PFSC, higher functions are now dictated to various conscious controls spread out through the brain. The integrative and centralized tendency seen so far progressing, from the periphery to the pons and midbrain, now expands to receive input from multiple other functional components, each integrating in itself complex interactions. Controlled experiments are difficult, as available experimental animal cannot be relied on to share similar structures and connections. Further progress, thus, required an entirely new toolset of investigation.

\section{Directions of Neurourological Research}

In the aging process or in disease states accompanied by neurological disorders, the cerebral control of suppression is weakened due to unnecessary activation of the micturition center. Nocturnal enuresis and accompanying lower urinary tract symptoms are sometimes thought to be caused by spinal reflexes that are not suppressed and controlled in the cerebrum. Therefore, if external local effects on inappropriate activation of the micturition center in the brain can be modified, these patterns of inappropriate activation can in turn be controlled, and may even be the target of treatment [62]. If confirmed, this is a promising possibility for our understanding of diseases accompanied by dysuria, such as aging and degenerative brain diseases, and it may facilitate the development of drugs to treat those diseases.

Currently, urodynamic studies are used for the definitive establishment of the phenotypic cause of disorders when diagnosing and treating patients with lower urinary tract dysfunction, including neurogenic dysfunction. Urodynamic studies enable a determination of whether the phenotype is myogenic, urotheliogenic, or neurogenic, and if it is neurogenic, they can shed light on the location of damage. Subsequently, any controllable pathophysiological factors related to the patient's condition are found and addressed as part of the treatment plan. However, this treatment strategy is only applicable to peripheral treatment targets. Therefore, an integrated research framework exploring the factors that hinder central inhibition in the micturition center, as discussed above, may lead to the identification of various methods to control factors that promote dysfunction. In other words, it is necessary to find tools for exploring the neurogenic phenotype.

The central focus of investigative tools reviewed thus far within this article shows how the discipline of neurourology is dependent upon understanding the specific compositional properties, and integrating this knowledge into the overall phenotypic expression of micturition and storage. The study of specific investigations has progressed from anatomical dissection to stereotactic lesions to rabies virus-mediated tracing, with the most advanced iteration presenting as the new science of optogenetics.

Optogenetics refers to the integration of optics and genetics to achieve gain or loss-of-function of well-defined events within specific cells of living tissue [63]. Discovery of bacterial opsin genes and rhodopsin proteins are distinct from vertebrate counterparts in that they do not couple to secondary messengers to influence ion channels, but directly transduce photons 
into electrical currents [64]. Though the initial discovery of rhodopsin-like proteins was expressed in bacteria had been made in the early 1970s, the technology to genetically clone expression to select neurons and then to be able to deliver select

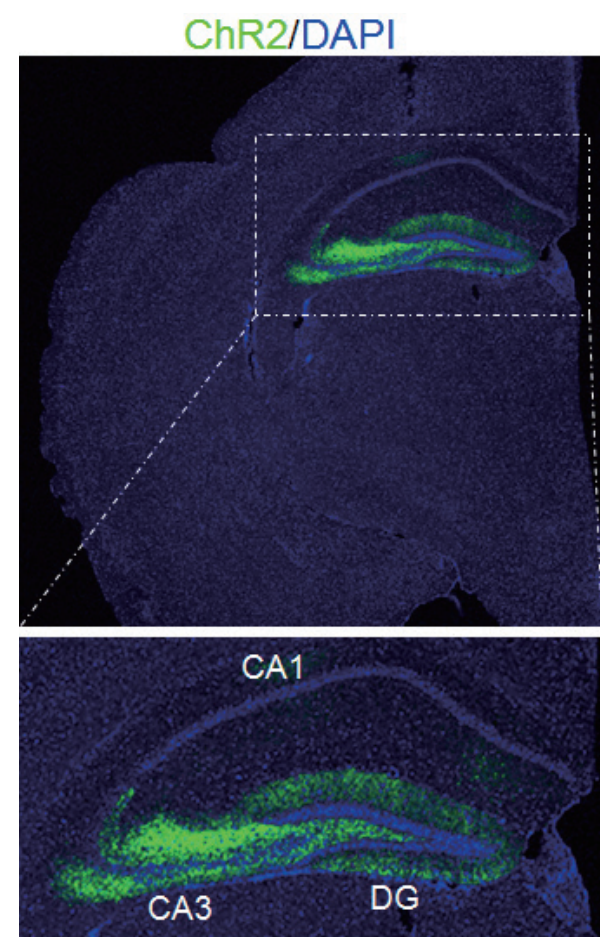

Fig. 2. Confocal image of expression of adeno-associated virus channelrhodopsin-2 (AAV-ChR2) (green) and DAPI (4',6-diamidino-2-phenylindole) (blue) at 3 weeks after AAV-ChR2 injection into the adult dentate gyrus (DG) shows incorporation of optogenetic modification to control detrusor overactivity in peripheral insult models, such as in interstitial cystitis/bladder pain syndrome [68]. frequencies of light required significant developmental challenges [65-67]. This new technology has gained rapid traction during the past decade. The recent trends of research delve into both the UMN and the LMN, investigating the spinal cord, the micturition centers of the pons and midbrain, as well as the pelvic neural ganglia [68-70] (Figs. 2, 3).

From an alternative perspective, physiological animal models which interpreted controlled experiments of dissected strips or anaesthetized animals can now be understood with fMRI images [71]. Artificial intelligence (AI) can be utilized from providing sharper images to conventional or novel techniques, control and perform complex optogenetic signal modulations, or simulate in silico models of control pathways. Modern development of AI has always reflected some aspect of neurology, whether it was from a ground-up development for the neural network-based perceptrons evolving into complex deep networks, or Bayesian-based symbolic AI developing from a relatively top-down position. However, the utility of AI in neuroscience is in itself too vast a topic to be covered in this review.

Yet, these methods are yet in their infancy, and are still limited when dealing with complex behavioral activity when it comes to humans. The basic mechanisms underlying these relationships have not been identified, meaning that specific methods to control such changes have not been developed. Observing and testing the roles of specific neurotransmitters and neuropeptides in controlling urination in the brain by activating and suppressing synaptic connections will make vital contributions to research into basic mechanisms in the field of neurourology [72]. Future investigations also point to an integrative approach.

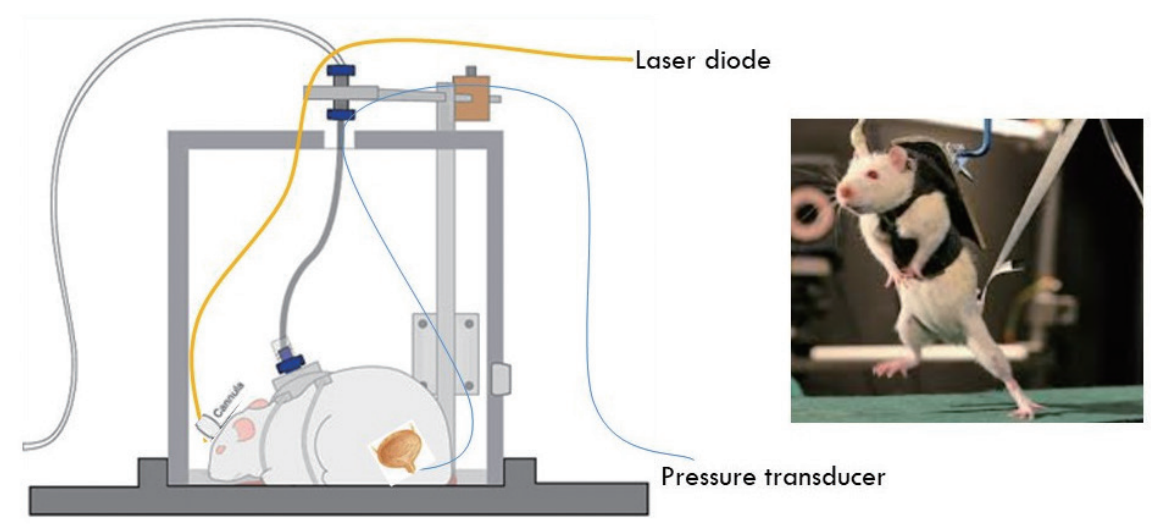

Fig. 3. Treadmill running model incorporated with optogenetic control of voiding centers. Such models show how conventional physiologic models of micturition can be complemented and incorporated with optogenetic studies [73]. 


\section{CONCLUSIONS}

The control of micturition is not isolated. The LMNs are interconnected with all pelvic functions from bowel movement to sexual stimuli, while the UMNs are deeply associated with emotions, social behavior, and pain. The association, not only with neurology and urology, but with speech rehabilitation, psychiatry, proctology, and sexual medicine opens up a complex avenue for investigation.

\section{AUTHOR CONTRIBUTION}

- Conceptualization: JWK, KHK

- Data curation: JWK, SJK

- Formal analysis: JWK, SJK

- Funding acquisition: $K H K$

- Project administration: $K H K$

- Visualization: $K H K$

-Writing-original draft: JWK

- Writing-review \& editing: JWK, SJK, KHK

\section{REFERENCES}

1. Griffiths J. Observations on the urinary bladder and urethra. J Anat Physiol 1891;25(Pt 4):535-49.

2. Vicary T, Furnivall JF, Furnivall P. The anatomie of the bodie of man. London: Early English text society; 1888.

3. Tortora GJ, Derrickson BH. Principles of anatomy and physiology. 15th ed. Hoboken (NJ): John Wiley \& Sons; 2018.

4. Lim SH, Wang TJ, Tseng GF, Lee YF, Huang YS, Chen JR, et al. The distribution of muscles fibers and their types in the female rat urethra: cytoarchitecture and three-dimensional reconstruction. Anat Rec (Hoboken) 2013;296:1640-9.

5. Jung J, Ahn HK, Huh Y. Clinical and functional anatomy of the urethral sphincter. Int Neurourol J 2012;16:102-6.

6. Fowler CJ, Griffiths D, de Groat WC. The neural control of micturition. Nat Rev Neurosci.2008;9:453-66.

7. Austin PF, Bauer SB, Bower W, Chase J, Franco I, Hoebeke P, et al. The standardization of terminology of lower urinary tract function in children and adolescents: update report from the Standardization Committee of the International Children's Continence Society. J Urol 2014;191:1863-5.e13.

8. Han JH, Kim SE, Ko IG, Kim J, Kim KH. Afferent pathway-mediated effect of $\alpha 1$ adrenergic antagonist, tamsulosin, on the neurogenic bladder after spinal cord injury. Int Neurourol J 2017;21:178-
88.

9. Purves D, Rubin E, Snider WD, Lichtman J. Relation of animal size to convergence, divergence, and neuronal number in peripheral sympathetic pathways. J Neurosci 1986;6:158-63.

10. Alsaid B, Bessede T, Karam I, Abd-Alsamad I, Uhl JF, Benoît G, et al. Coexistence of adrenergic and cholinergic nerves in the inferior hypogastric plexus: anatomical and immunohistochemical study with 3D reconstruction in human male fetus. J Anat 2009;214:64554.

11. Li L, Bi Y, Wang L, Mao X, Kraemer B, Lang J, et al. Identification and injury to the inferior hypogastric plexus in nerve-sparing radical hysterectomy. Sci Rep 2019;9:13260.

12. Onuf B. Notes on the arrangement and function of the cell groups in the sacral region of the spinal cord. J Nerv Ment Dis 1899;26: 498-504.

13. Marinesco G. Recherches sur les localisations motorices spinales. Sem Med (Paris) 1904;24:225-31.

14. Irimesco S, Parhon C. Recherches sur la localisation spinale de muscles du périnée st du rectum (chez l'homme). J Neurol (Paris) 1905;10:61-7.

15. Bertrand I. Etude de la cytoarchitectonie medullaire. Rev Neurol (Paris) 1923;30:312-34.

16. Laruelle L. Etude danatomie microscopique du nevraxe sur coupes longitudinales. Acta Neurol Psychiatr Belg 1948;48:189.

17. de Groat WC. Integrative control of the lower urinary tract: preclinical perspective. Br J Pharmacol 2006;147 Suppl 2(Suppl 2):S2540.

18. Tai C, Wang J, Jin T, Wang P, Kim SG, Roppolo JR, et al. Brain switch for reflex micturition control detected by FMRI in rats. J Neurophysiol 2009;102:2719-30.

19. Vizzard MA. Neurochemical plasticity and the role of neurotrophic factors in bladder reflex pathways after spinal cord injury. Prog Brain Res 2006;152:97-115.

20. Lee JM, Kim TW, Park SS, Han JH, Shin MS, Lim BV, et al. Treadmill exercise improves motor function by suppressing purkinje cell loss in parkinson disease rats. Int Neurourol J 2018;22(Suppl 3):S147-55.

21. Buchholz DW. Dysphagia associated with neurological disorders. Acta Otorhinolaryngol Belg 1994;48:143-55.

22. Onesti E, Schettino I, Gori MC, Frasca V, Ceccanti M, Cambieri C, et al. Dysphagia in amyotrophic lateral sclerosis: impact on patient behavior, diet adaptation, and riluzole management. Front Neurol 2017;8:94.

23. Kihira T, Yoshida S, Yoshimasu F, Wakayama I, Yase Y. Involvement of Onuf's nucleus in amyotrophic lateral sclerosis. J Neurol 
Sci 1997;147:81-8.

24. Doty RW, Bosma JF. An electromyographic analysis of reflex deglutition. J Neurophysiol 1956;19:44-60.

25. Tai C, Roppolo JR, de Groat WC. Spinal reflex control of micturition after spinal cord injury. Restor Neurol Neurosci 2006;24:69-78.

26. de Groat WC, Araki I, Vizzard MA, Yoshiyama M, Yoshimura N, Sugaya $\mathrm{K}$, et al. Developmental and injury induced plasticity in the micturition reflex pathway. Behav Brain Res 1998;92:127-40.

27. Barrington $F$. The effect of lesions of the hind-and mid-brain on micturition in the cat. Q J Exp Physiol 1925;15:81-102.

28. Pavcovich LA, Valentino RJ. Central regulation of micturition in the rat the corticotropin-releasing hormone from Barrington's nucleus. Neurosci Lett 1995;196:185-8.

29. Holstege G, Griffiths D, de Wall H, Dalm E. Anatomical and physiological observations on supraspinal control of bladder and urethral sphincter muscles in the cat. J Comp Neurol 1986;250:449-61.

30. Georgiadis JR, Kortekaas R, Kuipers R, Nieuwenburg A, Pruim J, Reinders AA, et al. Regional cerebral blood flow changes associated with clitorally induced orgasm in healthy women. Eur J Neurosci 2006;24:3305-16.

31. Holstege G. How the emotional motor system controls the pelvic organs. Sex Med Rev 2016;4:303-28.

32. Holstege G, Georgiadis JR, Paans AM, Meiners LC, van der Graaf $\mathrm{FH}$, Reinders AA. Brain activation during human male ejaculation. J Neurosci 2003;23:9185-93.

33. Holstege G, Kuypers HG, Boer RC. Anatomical evidence for direct brain stem projections to the somatic motoneuronal cell groups and autonomic preganglionic cell groups in cat spinal cord. Brain Res 1979;171:329-33.

34. Skultety FM. The behavioral effects of destructive lesions of the periaqueductal gray matter in adult cats. J Comp Neurol 1958;110: 337-65.

35. Sie JA, Blok BF, de Weerd H, Holstege G. Ultrastructural evidence for direct projections from the pontine micturition center to glycine-immunoreactive neurons in the sacral dorsal gray commissure in the cat. J Comp Neurol 2001;429:631-7.

36. Ding YQ, Wang D, Nie H, Guan ZL, Lü BZ, Li JS. Direct projections from the periaqueductal gray to pontine micturition center neurons projecting to the lumbosacral cord segments: an electron microscopic study in the rat. Neurosci Lett 1998;242:97-100.

37. Liu Z, Sakakibara R, Nakazawa K, Uchiyama T, Yamamoto T, Ito T, et al. Micturition-related neuronal firing in the periaqueductal gray area in cats. Neuroscience 2004;126:1075-82.

38. Blok BF, Holstege G. Direct projections from the periaqueductal gray to the pontine micturition center (M-region). An anterograde and retrograde tracing study in the cat. Neurosci Lett 1994;166:936.

39. Fanselow MS. The midbrain periaqueductal gray as a coordinator of action in response to fear and anxiety. In: Depaulis A, Bandler R, editors. The midbrain periaqueductal gray matter. Boston (MA): Springer; 1991. p. 151-73.

40. Gruber-Dujardin E. Role of the periaqueductal gray in expressing vocalization. Handb Behav Neurosci 2010;19:313-28.

41. Benarroch EE. Periaqueductal gray: an interface for behavioral control. Neurology 2012;78:210-7.

42. Hao S, Yang H, Wang X, He Y, Xu H, Wu X, et al. The lateral hypothalamic and BNST GABAergic projections to the anterior ventrolateral periaqueductal gray regulate feeding. Cell Rep 2019;28:61624.e5.

43. Blok BF, Holstege G. The pontine micturition center in rat receives direct lumbosacral input. An ultrastructural study. Neurosci Lett 2000;282:29-32.

44. Prabhakar AT, Iqbal Ahmed AS, Vijayakrishnan Nair A, Mathew V, Aaron S, Sivadasan A, et al. Neural correlates of urinary retention in lateral medullary infarction. Int Neurourol J 2019;23:205-10.

45. Wood SK, Baez MA, Bhatnagar S, Valentino RJ. Social stress-induced bladder dysfunction: potential role of corticotropin-releasing factor. Am J Physiol Regul Integr Comp Physiol 2009;296:R1671-8.

46. Ko IG, Kim SE, Kim CJ, Jung JH, Lee SJ, Kim DH, et al. Effect of treadmill exercise on leak-point pressure and neuronal activation in brain of rats with stress urinary incontinence. Int Neurourol J 2010;14:141-8.

47. Holstege $\mathrm{G}$. The emotional motor system and micturition control. Neurourol Urodyn 2010;29:42-8.

48. Cho YS. Importance of central regulation for lower urinary tract functions. Int Neurourol J 2018;22:1.

49. Jang HJ, Kwon MJ, Cho KO. Central regulation of micturition and its association with epilepsy. Int Neurourol J 2018;22:2-8.

50. Shy M, Fung S, Boone TB, Karmonik C, Fletcher SG, Khavari R. Functional magnetic resonance imaging during urodynamic testing identifies brain structures initiating micturition. J Urol 2014; 192:1149-54.

51. Harvie C, Weissbart SJ, Kadam-Halani P, Rao H, Arya LA. Brain activation during the voiding phase of micturition in healthy adults: $\mathrm{A}$ meta-analysis of neuroimaging studies. Clin Anat 2019;32:13-19.

52. Robbins MT, Uzzell TW, Aly S, Ness TJ. Characterization of thalamic neuronal responses to urinary bladder distention, including the effect of acute spinal lesions in the rat. J Pain 2006;7:218-24.

53. Chandler MJ, Hobbs SF, Fu QG, Kenshalo DR Jr, Blair RW, Foreman $\mathrm{RD}$. Responses of neurons in ventroposterolateral nucleus of 
primate thalamus to urinary bladder distension. Brain Res 1992; 571:26-34.

54. Kuhtz-Buschbeck JP, van der Horst C, Pott C, Wolff S, Nabavi A, Jansen $\mathrm{O}$, et al. Cortical representation of the urge to void: a functional magnetic resonance imaging study. J Urol 2005;174(4 Pt 1):1477-81.

55. Halani PK, Andy UU, Rao H, Arya LA. Regions of the brain activated in bladder filling vs rectal distention in healthy adults: A meta-analysis of neuroimaging studies. Neurourol Urodyn 2020; 39:58-65.

56. Blok BF. Central pathways controlling micturition and urinary continence. Urology 2002;59(5 Suppl 1):13-7.

57. Holstege G. Some anatomical observations on the projections from the hypothalamus to brainstem and spinal cord: an HRP and autoradiographic tracing study in the cat. J Comp Neurol 1987;260:98126.

58. Kavia RB, Dasgupta R, Fowler CJ. Functional imaging and the central control of the bladder. J Comp Neurol 2005;493:27-32.

59. Blok BF, van Maarseveen JT, Holstege G. Electrical stimulation of the sacral dorsal gray commissure evokes relaxation of the external urethral sphincter in the cat. Neurosci Lett 1998;249:68-70.

60. Athwal BS, Berkley KJ, Hussain I, Brennan A, Craggs M, Sakakiba$\mathrm{ra} \mathrm{R}$, et al. Brain responses to changes in bladder volume and urge to void in healthy men. Brain 2001;124(Pt 2):369-77.

61. Nour S, Svarer C, Kristensen JK, Paulson OB, Law I. Cerebral activation during micturition in normal men. Brain 2000;123(Pt 4): 781-9.

62. Salazar BH, Hoffman KA, Zhang C, Kavanagh A, Zhang Y, Boone $\mathrm{TB}$, et al. Electrical activity of the bladder is attenuated by intravesical inhibition of $\mathrm{P} 2 \mathrm{X} 2 / 3$ receptors during micturition in female rats. Int Neurourol J 2017;21:259-69.

63. Yizhar O, Fenno LE, Davidson TJ, Mogri M, Deisseroth K. Optogenetics in neural systems. Neuron 2011;71:9-34.

64. Deisseroth K. Optogenetics. Nat Methods 2011;8:26-9.

65. Oesterhelt D, Stoeckenius W. Rhodopsin-like protein from the purple membrane of Halobacterium halobium. Nat New Biol 1971;233:149-52.

66. Aravanis AM, Wang LP, Zhang F, Meltzer LA, Mogri MZ, Schneider MB, et al. An optical neural interface: in vivo control of rodent motor cortex with integrated fiberoptic and optogenetic technology. J Neural Eng 2007;4:S143-56.

67. Deisseroth K. Optogenetics: 10 years of microbial opsins in neuroscience. Nat Neurosci 2015;18:1213-25.

68. Kim SJ, Kim SW, Kim KH. MP39-03 Optogenetic modulation of micturition centers by basal forebrain-mediated neural circulatory activity in IC/BPS mice. J Urol 2018;199(4S):e510.

69. Ito H, Sales A, Drake M, Pickering AE. Novel model of micturition based on a multi-unit recordings of optogenetically-identified Barrington's CRH neurons in mice. Eur Urol Open Sci 2020;19:e679.

70. Keller JA, Chen J, Simpson S, Wang EH, Lilascharoen V, George O, et al. Voluntary urination control by brainstem neurons that relax the urethral sphincter. Nat Neurosci 2018;21:1229-38.

71. Karmonik C, Boone T, Khavari R. Data-driven machine-learning quantifies differences in the voiding initiation network in neurogenic voiding dysfunction in women with multiple sclerosis. Int Neurourol J 2019;23:195-204.

72. Kim KH. Expected next-generation drugs. Int Neurourol J 2017; 21:81-2.

73. Kim KT, Chang HK, Kim CH, Chung KJ, Brown S, Kim SJ, et al. Basic neurourology. J Exerc Rehabil 2019;15:747-50. 